\title{
Performance of Latex agglutination, ELISA and RT-PCR for diagnosis of Rotavirus infection
}

\author{
Hosna Hamzavi, ${ }^{1}$ Azarakhsh Azaran, ${ }^{2}$ Manoochehr Makvandi, ${ }^{2}$ Sahar Karami, ${ }^{1}$ \\ Mohammad Roayaei Ardakani, ${ }^{1}$ Amir Sasan Mozaffari Nejad ${ }^{3}$ \\ ${ }^{1}$ Department of Biology, Faculty of Science, Shahid Chamran University of Ahvaz, Iran; ${ }^{2}$ Department of virology, Ahvaz \\ Jundishapur University of Medical Sciences, Ahvaz, Iran; ${ }^{3}$ Molecular Research Center, Student Research Center, \\ Hamadan University of Medical Sciences, Hamadan, Iran
}

\begin{abstract}
The rotavirus is one of the major factors of inducing the acute gastroenteritis infection in children under 5 years of age. The laboratory diagnosis is progress and bringing it under control as well as avoiding its diffusion. The purpose of the present study was to determine the performance of enzyme linked immunosorbent assay (ELISA) and Latex agglutination (LA) tests against reverse transcription-polymerase chain reaction (RT-PCR) for evaluating the children's acute gastroenteritis by rotavirus.

One hundred feces specimens were collected from February to May 2014 and analyzed by LA, ELISA and RT-PCR.

In this study, the positive results for rotavirus detected by ELISA, LA and RT-PCR were 37, 43 and 27\%, respectively. In addition, the result showed that the sensitivity and specificity of ELISA and LA were 74 and $85 \%$, respectively, when compared to RT-PCR.

For laboratory detection of Rotavirus infection, RT-PCR has the highest sensitivity and specificity but because of the high
\end{abstract}

Correspondence: Amir Sasan Mozaffari Nejad, Hamadan University of Medical Sciences, Hamadan, Iran.

E-mail: as.mozafarinejad@umsha.ac.ir

Key words: Rotavirus; gastroenteritis; ELISA; LA; RT-PCR.

Contributions: the authors contributed equally.

Conflict of interest: the authors declare no potential conflict of interest.

Acknowledgements: the authors are thankful to the Vice-chancellor of Research of Shahid Chamran University of Ahvaz for funding the work through the research project No 9334252 .

Received for publication: 25 December 2016.

Revision received: 20 September 2017.

Accepted for publication: 22 October 2017.

(C) Copyright H. Hamzavi et al., 2017

Licensee PAGEPress, Italy

Journal of Biological Research 2017; 90:6522

doi:10.4081/jbr.2017.6522

This article is distributed under the terms of the Creative Commons Attribution Noncommercial License (by-nc 4.0) which permits any noncommercial use, distribution, and reproduction in any medium, provided the original author(s) and source are credited. costs, ELISA and LA based kits with good performance, as shown by this study, can be preferred for the routine use.

\section{Introduction}

According to the World Health Organization, nearly 20 to $30 \%$ of acute diarrhea cases known around the world are ultimately turned into lasting diarrhea, leading to poorly digested food, malnutrition and developmental insufficiency in the children. ${ }^{1}$ Amongst the factors inducing gastroenteritis, the viruses are the most common ones and the Rotavirus, Astrovirus and Adenovirus are most significant. ${ }^{2}$ Thirty three percent of diarrhea cases are caused by rotavirus. ${ }^{3}$ It is one of the causative agents of acute gastroenteritis in infants and young children around the world which is transmitted by fecal-oral root ${ }^{4}$ and also, belongs to the Reoviridae family and has a 20-fecet symmetry (Icosahedra), lack of coverage, and its genome is a double stranded RNA (dsRNA) and is formed by 11 segments. ${ }^{5,6}$ According to the reports, around 527000 children under 5 years old are dying annually as a result of rotavirus gastroenteritis. Over $85 \%$ of mortality occur in the low-income Asian and subSaharan African countries due to rotavirus. ${ }^{7}$ Every child under 5 years old is infected with rotavirus gastroenteritis at least once. ${ }^{8}$

It is seen that the children under 2 years old are mostly affected by rotavirus infection. This infection is a self-limited one; however, as a result of highly extracted body fluids as well as imbalance of electrolytes, the affected ones may be facing death, particularly in the developing countries. ${ }^{9}$ The function of conveying the nutrients to villi's cells of small bowel is disrupted by rotavirus without affecting the gastric mucosa and colon. ${ }^{10}$ The ratios estimated for the infection in Iran vary in different parts, ranging from $11.36 \%$ in Shiraz to $67.64 \%$ in Mazandaran to $79 \%$ in Tehran. The various variables such as geographical locations, periods of time, seasons and way of virus detection, age groups, gender and controlling the presence of non-diarrhea pathogens are involved in examination of disease prevalence. ${ }^{8}$

The viral particles are comprised of 3 protein layers. The structural proteins of VP1-4, VP6, and VP7 associated with non-structural proteins of NSP1- 6 are encoded by viral genome. ${ }^{11,12}$ The inner capsid is consisted of VP6 protein that is the most abundant viral protein. It is an appropriate target for detecting the infection caused by rotavirus. ${ }^{13}$ The rotaviruses are assigned to seven groups of $\mathrm{A}$ to $\mathrm{G}$ based on VP6 protein. The rotavirus belonging to group A is the most involved virus in infecting the human. In addition, 23 types of $\mathrm{G}$ and 32 types of P are distinguished by VP4 and VP7 antigens. The initial signs of infection induced by rotavirus are acute watery diar- 
rhea and vomiting and the patient needs to be hospitalized because of water deficit of the body. ${ }^{8}$

Several techniques for rotavirus diagnosis have been developed. The detection of rotavirus factor was first conducted by electron microscope, followed by techniques such as polyacrylamide gel electrophoresis (PAGE), immune-fluorescence (IF), radioimmuneassay (RIA), reverse passive hemagglutination (RPH), enzymelinked immunosorbent (ELISA) Latex agglutination test (LA) and, more recently reverse transcription-polymerase chain reaction (RTPCR) and immunochromatography (IMC). ${ }^{13}$

The aims of this study were to compare the function of three laboratory techniques to detect the rotavirus infection in children younger than 5 years of age with acute gastroenteritis.

\section{Materials and Methods}

\section{Sample collection}

This study was conducted in Aboozar children's hospital, Ahvaz city from Iran, hence, all the feces samples were collected on February to May 2014. The feces samples were taken from one hundred children who referred to the hospital with clinical signs of diarrhea, vomiting and fever. Using a questionnaire, the personality traits and nutritional habit of each patient along with the clinical symptoms such as diarrhea, vomiting, fever, blood in the stool, convulsions, runny nose, past history and disease severity were considered and recorded. Meeting such requirements as having an age less than 5 years and signs as diarrhea, vomiting and fever for less than 2 weeks was required for sampling, also, the clinical symptoms depending on the pathogen and the host defense mechanism is variable. ${ }^{14}$

Before sending the samples to the Research Center for Virologic Examination, the possible pathogens of bacterial or parasitic origins were studied together with the WBC and RBC counts in the blood. Each sample negatively detected in the Lab was poured into three different microtubes and by observing the cold chain and placing the samples on the ice, they were transferred to the laboratory of virology department in Ahvaz Jundishapur University of Medical Sciences and had been stored at $-70^{\circ} \mathrm{C}$ for varying times before use. In order to test the ELISA, the Generic Assay Germany Kit with a sensitivity of $98.4 \%$ and specificity of $100 \%$ was used and to do the Latex the Omega Diagnostic, England Kit with a sensitivity of 97.2 and specificity of $97.1 \%$ was introduced and registered in the Kit manual.

\section{Latex agglutination}

This test in term of qualitative detection is very rapid for diagnosing the rotavirus antibody. Nevertheless, the sensitivity and specificity of LA may vary according to the commercial kit used. The feces specimens were tested by LA Test [(Virotect ROTA OD038), Omega, England], the particles of latex were coated with antibody of antivirus. The sample was considered positive for rotavirus when agglutination was observed within two minutes reaction, as recommended by the kit manufacturer.

\section{Enzyme-linked immunosorbent assay}

ELISA is a simple technique that enjoys some advantages as portability of the equipment, hand-holding validation, and reliability for the assessment of samples. ${ }^{15-17}$ All feces samples were tested by commercial ELISA test kit (Generic Assays, Germany) according to the method described by manufacturer's instructions.

\section{Reverse transcription-polymerase chain reaction}

The extraction of viral RNA was conducted by utilizing the RNA purification and Gene JET Viral DNA Kits, made by Ferments $\mathrm{Co}$, South Korea. It is notable that the extracted RNA was stored in the freezer $-70^{\circ} \mathrm{C}$ until fabrication of cDNA. In this phase, the extracted RNA was transformed to CDNA using AccuPower ${ }^{\circledR}$ CycleScript RT PreMix (dN12) Bioneer Co, South Korea.

Values for PCR reaction were as follows: VP6-Forward: GACGGV(c)GCR(b)ACTACATGGT ${ }^{18}$ VP6-Reverse: GTCCAATTCATN(d)CCTGGTG [c= $(\mathrm{N}=\mathrm{A}, \mathrm{T}, \mathrm{C}$ or $\mathrm{G}), \mathrm{b}=(\mathrm{R}=\mathrm{A}$ or $\mathrm{G}), \mathrm{d}=(\mathrm{Y}=\mathrm{C}$ or $\mathrm{T})] .{ }^{19}$

The reaction mixture contained $2.5 \mu \mathrm{L}$ PCR reaction buffer $10 \mathrm{X}$ (Cinnagen, Iran) with $0.25 \mathrm{MgCl}_{2} 50 \mathrm{mM}$ (Cinnagen, Iran), $0.5 \mu \mathrm{L}$ dNTPs $10 \mathrm{mM}$ (Cinnagen, Iran), $0.2 \mu \mathrm{L}$ of Taq DNA polymerase $2 \mathrm{U}$ (Cinnagen, Iran), $0.25 \mu \mathrm{L}$ of each primer $(100 \mathrm{~mol})$ and $2 \mu \mathrm{L}$ of the template. PCR was performed on Techne Thermal Cycler (UK) for 35 cycles. Cycling conditions were as follows: $95^{\circ} \mathrm{C}$ for $10 \mathrm{~min} ; 35$ cycles at $94^{\circ} \mathrm{C}$ for $45 \mathrm{sec}, 55^{\circ} \mathrm{C}$ for $45 \mathrm{sec}, 72^{\circ} \mathrm{C}$ for $45 \mathrm{sec}$, and a final elongation at $72^{\circ} \mathrm{C}$ for $10 \mathrm{~min}$. The expected PCR product was $382 \mathrm{bp}$. The PCR product was subjected to electrophoresis on a $2 \%$ agarose gel, stained with DNA safe stain, and observed under ultraviolet light. For the positive control, positive samples in the samples archive which had previously been sequenced were used ${ }^{20}$ and for the negative control, the sterile deionized was water.

\section{Statistical analysis}

The data was analyzed by SPSS for windows TM version 19 and Microsoft Excel for windows 2007 using Pearson test (rho) for correlation between the variables. The differences among the mean values were found to be significant at $\mathrm{P} \leq 0.05$.

\section{Results}

In this study, 100 children with acute gastroenteritis by the age range of 1 to 60 months to detect rotavirus antigens in stool samples were studied. There rotavirus in 27 samples were found positive by RT-PCR test of which only 26 cases were positive immunoferment 24 by LA test. ELISA a sample of 62 negative samples $(1.61 \%)$ and 54 negative samples latex three samples (5.55\%) were detected positive by RT-PCR test. By comparison, the sensitivity and specificity for LA test and ELISA were 89, 74, 96 and $85 \%$, respectively. Comparison was made on the assumption that the samples tested by RT-PCR were positive or negative. Also, the PPV, NPV, FP and FN have been reported in Table 1.

Among the positive samples with rotavirus, $59.25 \%$ were male and $40.74 \%$ were female. The majority of positive cases of rotavirus in children under 2 years were $88 / 89 \%$ and the largest number was among the 6 to 8 month age group (29.62\%) was observed in Table 2.

\section{Discussion}

Rotavirus (RV) is the main etiological agent of diarrhea in infants and young children worldwide, accounting for 30 to $50 \%$ of acute diarrheal illnesses; hence, its laboratory diagnosis is crucial to guide the clinical management and prevention of its spread. ${ }^{20,21}$

The specific detection of produced infection by rotavirus is carried out by studying the feces samples through Enzyme Immunoassay techniques with diagnostic Kits, for its having high 
detection speed, high sensitivity and specificity; and are applied for diagnosing all the serotypes of rotavirus. ${ }^{22,23}$ In addition, these kits are employed for detecting the animal rotavirus infection. ${ }^{22}$ The most used tests in detecting the rotavirus infection are electron microscope, LA, ELISA, Immunofluorescence PAGE as well as molecular tests. ${ }^{24}$ In this study, the comparison of ELISA and LA methods compared to RT-PCR and the result showed higher sensitivity and high specificity of RT-PCR. The highest sensitivity was (96\%) obtained for ELISA followed by LA (89\%). While the highest specificity was (85\%) obtained for ELISA followed by LA (74\%). Moreover, these results calculated for the positive predictive value (PPV) of ELISA and LA were 70.3 and $55.81 \%$, respectively, and, the negative predictive value (NPV) of ELISA and LA were 98.4 and $94.74 \%$, respectively. Although the rapid detection of viral specimens is easier with ELISA and LA methods, the disadvantages of these methods in this test are high for FP and NP values. Each factor is due to the high values of these parameters, including how samples are collected, how samples are transferred, or how any action that contributes to changes in the number of rotavirus in the samples are taken.

The previous survey by Buesa et al. ${ }^{25}$ compared RT-PCR, ELISA, PAGE and electron microscope. The positive rate was obtained as 30, 29, 26.85 and $25.45 \%$ for PCR, ELISA, PAGE and electron microscope, respectively. Although, the results have shown that LA for detecting the presence of antigen is associated with high sensitivity and good specificity, but ELISA test is of good sensitivity and high specificity. Both tests easily detect the infection with high speed. Nevertheless, the LA test is used in detecting the rotavirus in laboratory of hospitals or in private practice of the physicians for fast diagnosis. ${ }^{26}$ However, the ELISA can

Table .1 Compare ELISA and LA test against RT-PCR test.

\begin{tabular}{lcc}
\hline Parameters & LA\% & EISA\% \\
Sensitivity & 89 & 96 \\
Specificity & 74 & 85 \\
\hline Positive Predictive Value (PPV) & $55 / 81$ & $70 / 3$ \\
Negative Predictive Value (NPV) & $94 / 74$ & $98 / 41$ \\
\hline False Positive (FP) & $44 / 2$ & $29 / 7$ \\
False Negative (FN) & $5 / 55$ & $1 / 61$ \\
\hline
\end{tabular}

Table 2. The positive characteristics of the study sample.

\begin{tabular}{lcc} 
Parameters & $\begin{array}{c}\text { Rotavirus positive samples } \\
\text { n }\end{array}$ & (N=27) \\
Sex & 16 & 59.25 \\
$\quad$ Male & & \\
$\quad$ Female & 11 & 40.74 \\
Age (month) & & \\
$0-12$ & 16 & 59.25 \\
$13-24$ & 8 & 29.63 \\
$25-36$ & 2 & 7.41 \\
$37-60$ & 1 & 3.7 \\
Clinical symptoms & & \\
Diarrhea & 25 & 92.59 \\
Vomiting & 24 & 88.9 \\
Fever & 21 & 77.8 \\
\hline
\end{tabular}

be utilized for screening the aggregate. ${ }^{27}$ Also, the other study by Steele $e t a l .{ }^{28}$ revealed that two methods by ELISA and LA were compared. They argued that the ELISA is fast and with significant sensitivity $(100,96 \%)$ and can be used for aggregate screening that is consistent with our results. The conducted research study by Eing et $a .^{22}$ examined two different ELISA, labeled as RIDASCREEN $^{\circledR}$ rotavirus and Path finder rotavirus, in 393 patients. Both tests had $100 \%$ sensitivity as well as positive predicative value 93.7 and $57.7 \%$, respectively. The previous survey by Ibrahim et al. ${ }^{29}$ reported that LA has a high sensitivity of $96 \%$ but its specificity is the lowest. Also, the electron microscope and PAGE have $100 \%$ sensitivity and their specificity is 73 and $84 \%$, respectively.

The other survey from Baghdad, which examined the performance of ELISA and LA in detecting gastroenteritis infection, showed the sensitivity and specificity for ELISA and LA were 92.5, 86.3\% and $84.09,93.6 \%$, respectively. The reaction percentage of false positive for LA was $7.7 \%$ over that of $3.3 \%$ for ELISA. ${ }^{13}$

In a survey by Altindis et al. ${ }^{24}$ it was reported that the three methods of LA, ELISA and gel electrophoresis polyacrylamide were used for detecting rotavirus. Being positive for rotavirus test was reported by three above methods as $12.59,15.55$ and $11.85 \%$, respectively. The sensitivity and specificity of ELISA and LA over PAGE were expressed as 100, 99.16 and $93.75,94.96 \%$, respectively. Both methods had high sensitivity and specificity. The other study showed that the laboratory detection of rotavirus infection and the effect of immunizing on hospitalization. By comparing the three methods of ELISA, LLA in detecting rotavirus antigen and PAGE in detecting RNA, they concluded that the ELISA was more specific with higher sensitivity of $94.6 \%$ and specificity of $94.4 \%$, accuracy of $94.5 \%$ and high detection speed. The percentage of being positive for ELISA, LA and PAGE was obtained 28.3, 34.8 and $25.6 \%$, respectively. Also, this study showed the occurrence of rotavirus infection since implementation of global safety programs. For LA test, the sensitivity was obtained 82.6 and $81.6 \%$ which are consistent with our results. ${ }^{30}$

\section{Conclusions}

Rotavirus detection is greatest when diarrhea, vomiting, and fever occur together and lowest when each symptom occurred alone. Diagnosis of the infection is based on the identification of the virus in feces or suspension of rectal swab collected early in the illness through direct microscopy, molecular techniques, rapid serological tests, and the use of tissue culture technique. The results indicateed that the LA and ELISA kit used for rotavirus diagnosis presented good sensitivity, high specificity, and easy proceeding, providing fast diagnosis for rotavirus infections. Also, these techniques indeed influence clinicians in the implementation of effective management and control measures to pediatric rotavirus diarrhea disease. Hence, these methods may thus be used as a reliable test for diagnosis of rotavirus infection.

\section{References}

1. Maleki E, Diae Parizi MH, Arabzadeh S. Relative frequency of Rotaviro gastroenteritis in children below 3 years old with acute gastroenteritis referred to Afzalipour hospital in autumn 2008. J Kerman Univ Med Sci 2010;17:130-6. 
2. Hamkar R, Yahyapour Y, Noroozi M, et al. The prevalence of viral agents in children with acute gastroenteritis in Mazandaran province. Iran J Infect Dis Trop Med 2008;12:35-40.

3. Moradi AV, Mokhtari Azad T. Rotavirus infection in under 6 years old children with acute diarrhea. Tabib-e-Shargh, Zahedan J Res Med Sci 2001;1:23-8.

4. Ansari SA, Springthorpe VS, Sattar SA. Survival and vehicular spread of human rotaviruses: possible relation to seasonality of outbreaks. Rev Infect Dis 1991;13:448-61.

5. Bishop R, Davidson GP, Holmes IH, Ruck BJ. Virus particles in epithelial cells of duodenal mucosa from children with acute non-bacterial gastroenteritis. Lancet 1993;302:1281-3.

6. Brook G, Butel J, Caroll K, Morse S. Medical Microbiology. $24^{\text {th }}$ ed. New York: McGraw Hill Company; 2007.

7. CDC. Rotavirus Surveillance Worldwide, 2001-2008. MMWR 2008;57:1255-7.

8. Lakeh MM, Shakerian S, Yaghoubi M, et al. Rotavirus infection in children with acute gastroenteritis in Iran: a systematic review and meta-analysis. Int J Prev Med 2014;5:1213-23.

9. Raboni SM, Nogueira MB, Hakim VM, et al. Comparison of latex agglutination with enzyme immunoassay for detection of rotavirus in fecal specimens. Microbiology and Infectious Disease. Am J Clin Pathol 2002;117:392-4.

10. Feigin RD, Cherry J, Demmler-Harrison GJ, et al. Textbook of pediatric infectious Diseases. $4^{\text {th }}$ ed, Philadelphia, PA: Saunders; 1998 .

11. Desselberger U. Molecular epidemiology of rotaviruses. In: Farthing M, ed. Viruses and the gut, London: Swan; 1989.

12. Estes M. Rotaviruses and their replication. In: Knipe D, Howlwy P, eds. Fields virology. $4^{\text {th }}$ ed. Philadelphia. Lippincott. Williams \& Wilkins; 2001.

13. Dennehy PH. Rotavirus vaccines: an overview. Clin Microbiol Rev 2008;21:198-208.

14. Cortese F, Scicchitano P, Gesualdo M, et al. Early and late infections in newborns: where do we stand? A review. Pediatr Neonatol 2016;57:265-73.

15. Mozaffari Nejad AS, Bayat M, Ahmadi AA. Investigation of aflatoxin B1 in spices marketed in Hyderabad, India by ELISA method. J Pure Appl Microbiol 2013;7:3219-23.

16. Mozaffari Nejad AS, Ghannad MS, Kamkar A. Determination of aflatoxin B1 levels in iranian and indian spices by ELISA method. Toxin Rev 2014;33:151-4.

17. Eslami M, Mashak Z, Heshmati A, et al. Determination of aflatoxin $\mathrm{B} 1$ levels in iranian rice by ELISA method. Toxin Rev 2015;34:125-8.

18. Iturriza-Gómara M, Kang G, Gray J. Rotavirus genotyping: keeping up with an evolving population of human rotaviruses. J Clin Virol 2004;31:259-65.

19. Gómara MI, Wong C, Blome S, et al. Molecular characterization of VP6 genes of human rotavirus isolates: correlation of genogroups with subgroups and evidence of independent segregation. J Virol 2002;76:6596-601.

20. Azaran A, Makvandi M, Samarbafzadeh A, et al. Study on Rotavirus infection and its genotyping in children below 5 years in South West Iran. Iran J Pediatr 2016;26:2080.

21. Ghazi HO, Khan MA, Telmesani AM, et al. Rotavirus infection in infants and young children in Makkah. Saudi Arabia J Pak Med Assoc 2005;55:231-4.

22. Eing BR, May G, Baumeister HG, Kühn JE. Evaluation of two enzyme immunoassays for detection of human Rotaviruses in fecal specimens. J Clin Microbiol 2001;39:4532-4.

23. Maes RK, Grooms DL, Wise AG, Han C, Ciesicki V, Hanson L, Vickers ML, Kanitz C, Holland R. Evaluation of a human group a rotavirus assay for on-site detection of bovine rotavirus. J Clin Microbiol 2003;41:290-4.

24. Altindis M, Yavru S, Simsek A, Ozkul A, Ceri A, Koc H. Rotavirus infection in children with acute diarrhea as detected by latex agglutination, ELISA and polyacrylamide gel electrophoresis. Indian Pediatr 2004;41:590-4.

25. Buesa J, Colomina J, Raga J, et al. Evaluation of reverse transcription and polymerase chain reaction (RT/PCR) for the detection of rotaviruses: applications of the assay. Res Virol 1996; 147:353-61.

26. Buser J, Risch L, Rutz T, et al. Comparison of a rotavirus latex agglutination test with two rapid immunochromatographic test devices for detection of rotavirus in human feces. Eur J Clin Microbiol Infect Dis 2001;20:295-6.

27. Saravanan P, Ananthan S, Sundaram A. Comparative analysis of monoclonal antibodies based enzyme immunoassay modified genome electrophoresis and electron microscopy procedures for rotavirus diagnosis from fecal specimens. Indian $\mathrm{J}$ Med Res 2001;113:78-82.

28. Steele AD, Williams MM, Bos P, Peenze I. Comparison of two rapid enzyme immunoassays with standard enzyme immunoassay and latex agglutination for the detection of human rotavirus in stools. J Diarrheal Dis Res 1994;12:117-20.

29. Ibrahim OS, Sunderland D, Hart CA. Comparision off our methods for detection of rotavirus in feces. Trop Doctor 1990;20:30-2.

30. Pereira LA, Raboni SM, Nogueira MB, et al. Rotavirus infection in a tertiary hospital: laboratory diagnosis and impact of immunization on pediatric hospitalization. Braz J Infect Dis 2011;15:215-9. 